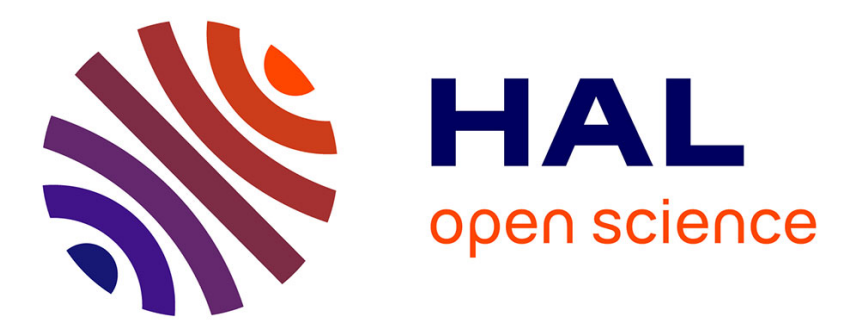

\title{
Development of RF heating and current drive systems for long pulse operation on Tore Supra
}

G. Agarici, J. P. Allibert, J.M. Ane, R. Arslanbekov, J.F. Artaud, S. Balme, V. Basiuk, P. Bayetti, L. Baylor, A. Becoulet, et al.

\section{- To cite this version:}

G. Agarici, J. P. Allibert, J.M. Ane, R. Arslanbekov, J.F. Artaud, et al.. Development of RF heating and current drive systems for long pulse operation on Tore Supra. AIP Conference Proceedings, 2008, pp.23-31. 10.1063/1.53382 . hal-03534486

\section{HAL Id: hal-03534486 \\ https://hal.science/hal-03534486}

Submitted on 19 Jan 2022

HAL is a multi-disciplinary open access archive for the deposit and dissemination of scientific research documents, whether they are published or not. The documents may come from teaching and research institutions in France or abroad, or from public or private research centers.
L'archive ouverte pluridisciplinaire HAL, est destinée au dépôt et à la diffusion de documents scientifiques de niveau recherche, publiés ou non, émanant des établissements d'enseignement et de recherche français ou étrangers, des laboratoires publics ou privés. 


\section{Development of RF heating and current drive systems for long pulse operation on Tore Supra}

Cite as: AIP Conference Proceedings 403, 23 (1997); https:// doi.org/10.1063/1.53382

Published Online: 09 April 2008

B. Beaumont
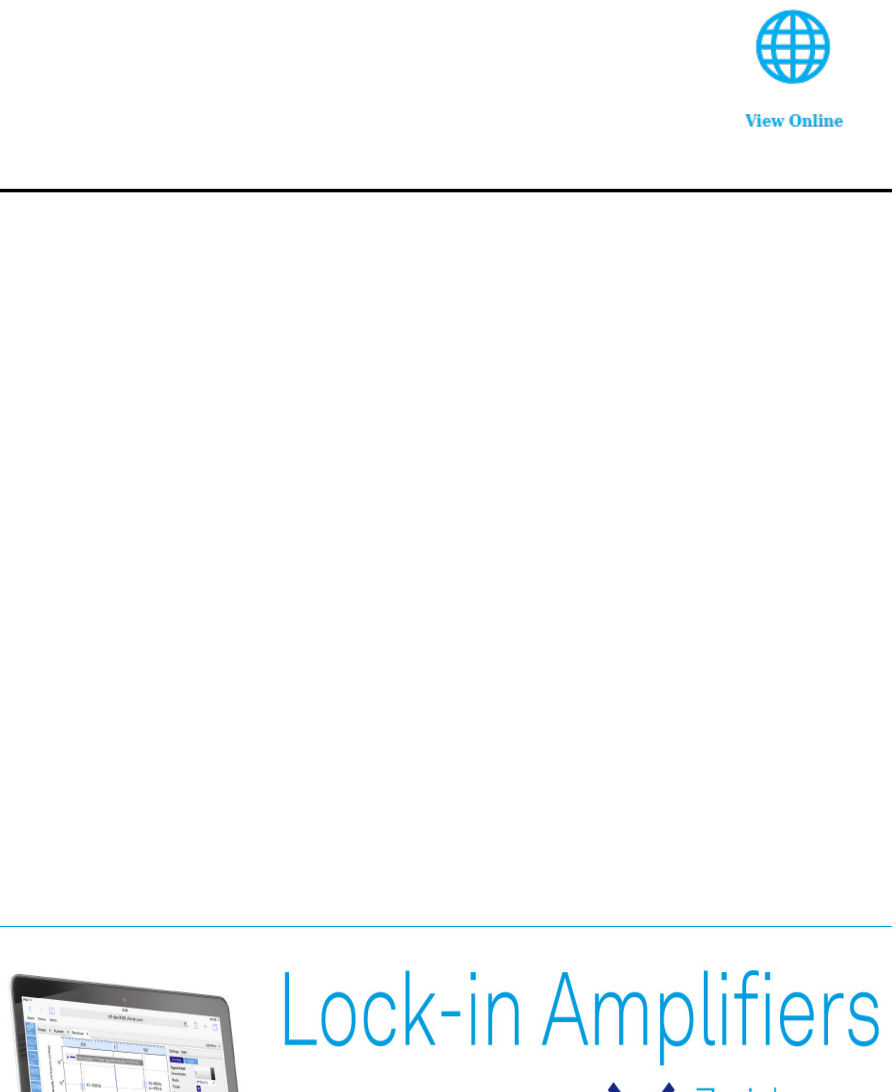

Zurich

Instruments

Watch the Video $>$ 


\title{
Development of RF Heating and Current Drive Systems for Long Pulse Operation on \\ Tore Supra
}

\author{
Equipe Tore Supra ${ }^{\#}$, presented by B.Beaumont.
}

DRFC, Association Euratom-CEA, C.E. Cadarache, 13108 Saint Paul-Lez-Durance, France

\begin{abstract}
Significant results on steady state control of the plasma parameters have been obtained with RF systems on Tore Supra. A sustained effort is under way to improve power transmission reliability. Developments of sources and antennas are in progress for future operation on Tore Supra with pulse length in the range of several hundreds of seconds.
\end{abstract}

\section{SIGNIFICANT RESULTS WITH RF SYSTEMS FOR STEADY STATE PLASMA CONTROL}

A large experience on long pulse (up to $2 \mathrm{mn}$ ) operation has been gathered on Tore Supra (1). These experiments are used to qualify scenarios and equipment for future operation during several hundreds of seconds. The goal is to be able to sustain the plasma for as long as 1000 s.

The longest shot to date performed on Tore Supra is the shot \#19980. It lasted $120 \mathrm{~s}$, as $2.4 \mathrm{MW}$ of LHCD were injected in the plasma to sustain the major part, $90 \%$, of the $0.8 \mathrm{MA}$ plasma current (Fig. 1). The total injected energy reached 280 MJ. A LHEP mode with $\mathrm{H}=1.4$ compared to the ITER-96 L-mode (2) scaling was achieved throughout the discharge. The conditions for the plasma itself are not steady state: a slight density increase is observed after 1 minute, suggesting outgassing from a not yet cooled surface receiving a thermal flux. On the contrary, for the parameters shown concerning the LHCD system, such as the reflected fraction of the injected power, the pressure in the waveguide array, or the surface temperatures of the front face of the grill, stationary conditions are observed at this power level.

A plasma of $0.8 \mathrm{MA}$ at full current drive has also been obtained for $75 \mathrm{~s}$ with $\mathrm{LH}$ alone. An average LH power density of $24 \mathrm{MW} / \mathrm{m}^{2}$ was achieved on one of the launchers located $85 \mathrm{~mm}$ from the plasma LCFS. 

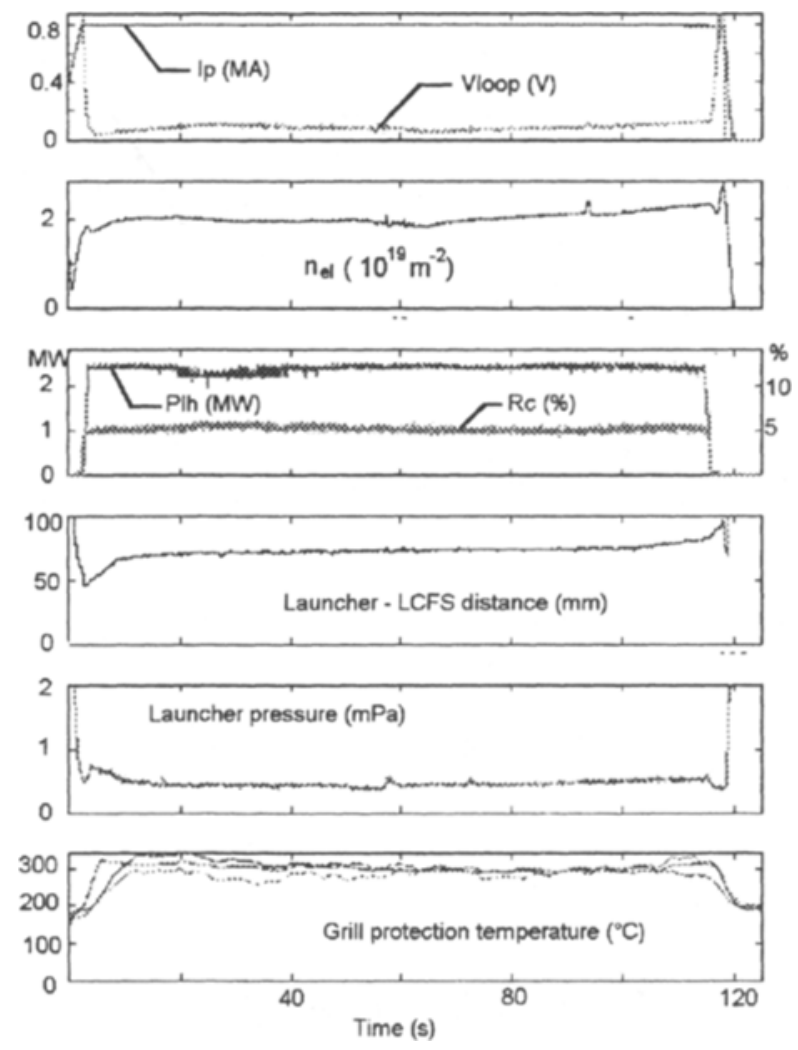

FIGURE 1. 120 s pulse with $280 \mathrm{MJ}$ injected energy.

The deduced electric field inside the multijunctions is around $5.4 \mathrm{kV} / \mathrm{cm}$. No impurity influx was observed and steady state regime at the grill was established. This discharge is used to validate the choice of $25 \mathrm{MW} / \mathrm{m}^{2}$ for the nominal power density of the future LHCD launcher for Tore Supra described later in part 3.

Long discharges operation requires several feedback controls on plasma parameters (3). The LHCD system has demonstrated its ability to sustain $100 \%$ of the plasma current for long discharges by a double control of the LH power by the current and the loop voltage by the primary transformer. Further experiments (4) have also proved the possibility to control the internal inductance with the phasing of the LH array while the plasma current is driven by the LH power itself (Fig. 2). 

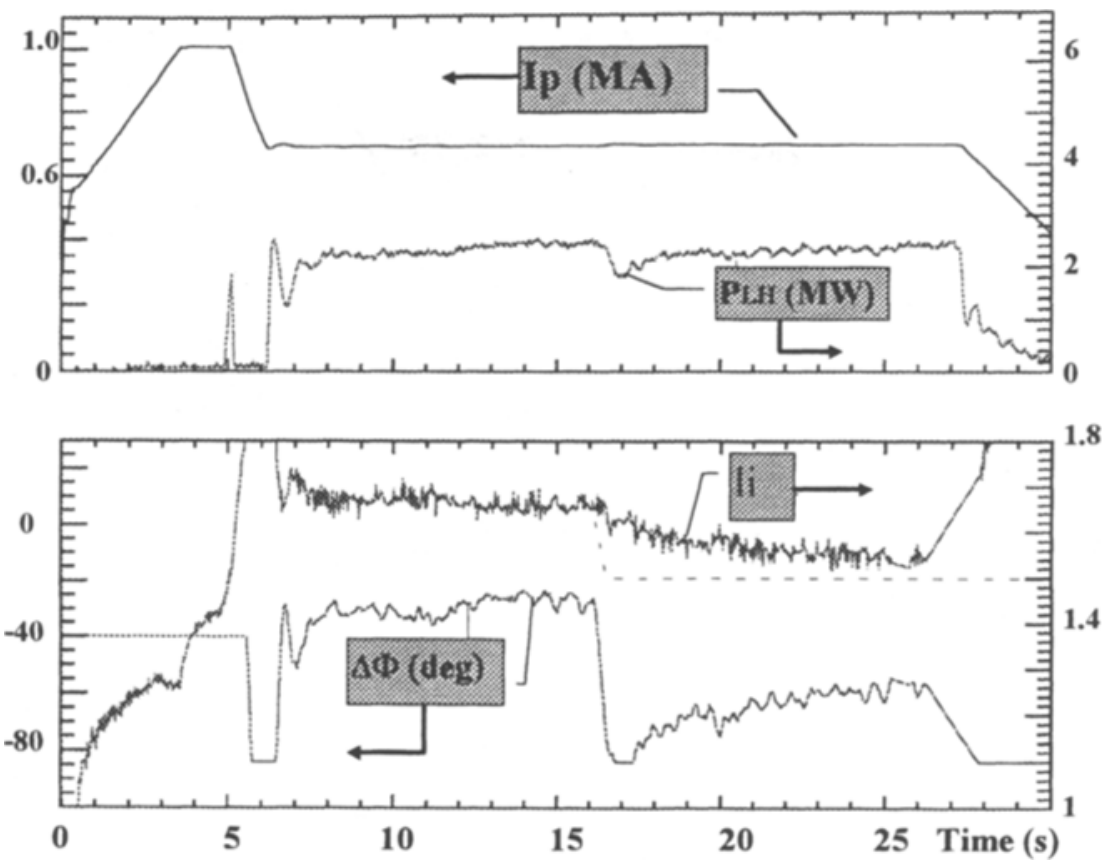

FIGURE 2. feedback control of $L H$ power on Ip and $\Delta \Phi$ on li

Proposed advanced scenarios will use the bootstrap current as a significant part of the total current. An approach to such a scenario has been studied for a duration of $5 \mathrm{~s}$ (Fig. 3), during which $6 \mathrm{MW}$ of FWEH triggered a bootstrap fraction of nearly $45 \%$. Steady state conditions were observed on the energy confinement, central electron temperature, density, and impurity content (5).

\section{FUTURE SCENARIOS FOR LONG PULSE OPERATION}

A project to upgrade the internal components and limiters of Tore Supra for discharges up to $1000 \mathrm{~s}$ is in progress. A detailed design of a new toroidal pumped limiter, associated with a new wall protection is being studied and the fabrication will lead to an installation in TS in 1999. The goal of this new set of internal components is to be able to extract $25 \mathrm{MW}$ of input power with a typical partition of $10 \mathrm{MW}$ as radiated power, and $15 \mathrm{MW}$ convected to the limiter (6). This limiter will provide active density control for plasmas with $\left\langle\mathrm{n}_{\mathrm{e}}\right\rangle$ in the range of $5.10^{19} \mathrm{~m}^{-3}$. High density operation will tend to increase the radiated power and equipartition. Coupling of both LH and FW power will be increased, but the net RF driven current is decreased, so that steady state operation at $\mathrm{Ip}=1.7 \mathrm{MA}$ is possible only 
around $\left\langle\mathrm{n}_{\mathrm{e}}>\approx 2.10^{19} \mathrm{~m}^{-3}\right.$. For high density operation, the scenario will use a high bootstrap fraction. Current profile will be controlled to obtain an improved confinement, which will balance in term of energy content the effect of the necessary reduction of the plasma current. The performances of the TS RF systems need to be upgraded for compatibility with the long pulse requirements. RF sources and coupling structures, initially designed for shorter pulses, are being transformed to meet this new requirement.

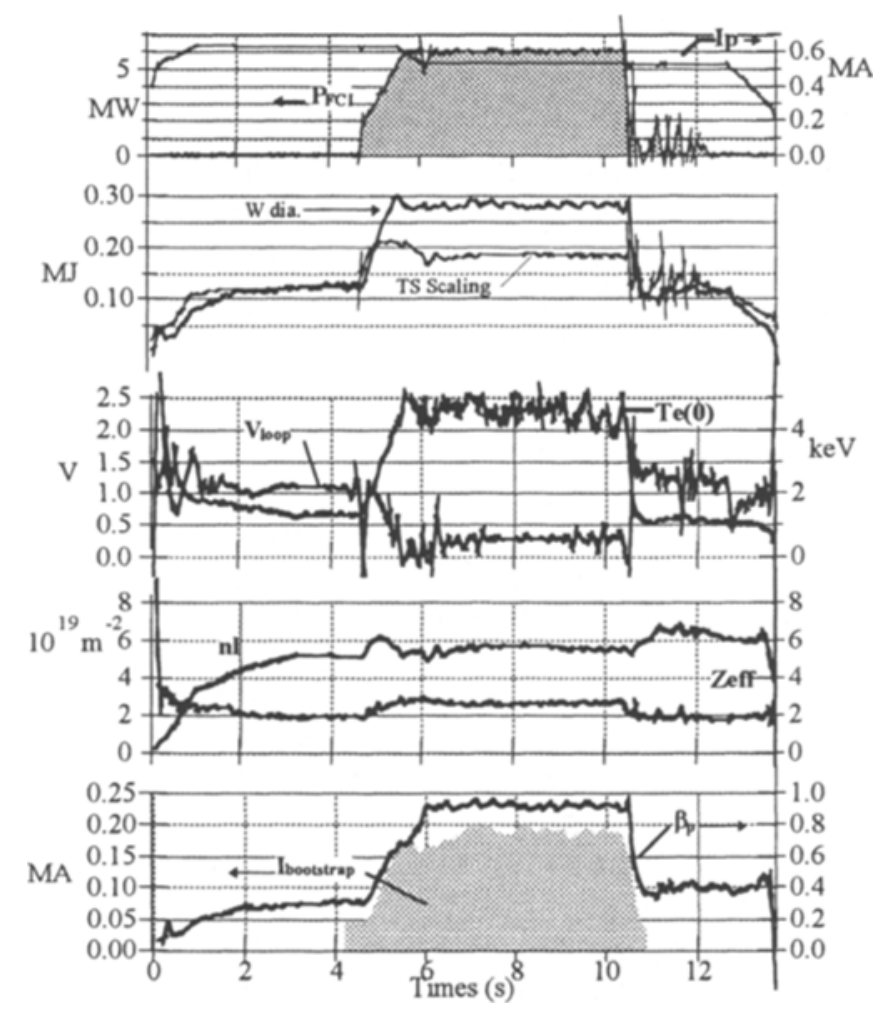

FIGURE 3. \#18805 : high bootstrap fraction driven by FWEH

\section{TECHNICAL DEVELOPMENTS OF RF SYSTEMS}

ICRH and LHCD systems have been widely used on TS. The level of coupled power with the ICRH is ranging from 9.3MW during $2 \mathrm{~s}$ to $2 \mathrm{MW}$ during $27 \mathrm{~s}$, and for LHCD from 6MW during $2 \mathrm{~s}$ to $2.4 \mathrm{MW}$ during $120 \mathrm{~s}$. 


\section{ICRH System}

The ICRF studies on TS is a field of collaboration with the US-DOE, with a special involvement of ORNL, and with ASIPP (China). The ICRH system on TS is using 3 Resonant Double Loop antennas fed by 6 high power tetrode generators. Recent developments have dealt with generator upgrades and antenna matching systems. The high power tetrodes have been enhanced by modifying the anode internal cooling circuit : the water is forced through holes in the thick anode wall. Special care in the design of the channels has allowed to keep the pressure drop through the tetrode at an acceptable level : $1.710^{5} \mathrm{~Pa}$ for $800 \mathrm{l} / \mathrm{mn}$, and a corresponding anode dissipation of $2 \mathrm{MW} @ 60 \mathrm{MHz}$.

Long pulse testing of these tetrodes at Thomson Tubes Electroniques (TTE) have established the power limit for very long pulses $(45 \mathrm{mn})$ on a VSWR $\approx 1.1$ load. The thermal equilibrium is reached after $1000 \mathrm{~s}$, and the limit is at the 1.5 MW level. This limit is due to the thermal equilibrium of the grids inside the tube. As the size and geometry is fixed by the frequency range, there is no way to improve this limit in a noticeable way on conventional tetrodes. The present tubes are using pyrolitic graphite grids which are already giving the best results in term of losses (outgassing rate, overheating and thermoemission level). For higher output power, TTE is developing a new kind of tetrode, the Diacrode ${ }^{\circledR}$, which will allow to double the output power level. Combined with an efficient cooling circuit on the anode, these tubes should allow to reach $2 \mathrm{MW} \mathrm{CW}$ on a VSWR $\approx 2$ load, any phase. This goal is at the same level as the present day ITER requirements. The preliminary test of the first prototype is scheduled for the end of 1997.

The TS antennas are now equipped with an automatic matching system. A closed loop control of the position of the matching capacitors allows to keep the VSWR below 1.2 during the pulse. Response time is today around $200 \mathrm{~ms}$, and the stability studies of the loop should permit to lower this value around $50 \mathrm{~ms}$. For faster response, an electrical circuit with no mechanical adjustment will need to be studied : matching optimisation could be performed either by frequency tracking or by recirculation of the reflected power to a dummy load.

Hot spots have been observed on antennas lateral protections, and lead to damages on the protective tiles. In parallel with studies of this specific RF/edge interaction (7), a new design is being developed. This design will use the same technology as the future toroidal pumped limiter for the plasma facing elements : CFC tiles bonded on copper alloy water cooled fingers. Both the toroidal and poloidal extension will be increased and improvement of performances is foreseen from the tougher design and larger surface (Fig. 4).

Qualification of RF contacts for use in vacuum has been undertaken. The use of sliding contacts in vacuum has until now been avoided by lack of confidence in the technical solution. Different contact surfaces and materials are being tested : a commercial RF contact has been successfully tested up to 1000 A r.m.s. for a 60 $\mathrm{mm}$ diameter coaxial conductor with pulse length of 60 s (8). These contacts could 
be used in a new type of vacuum matching or in vacuum stub tuners which could be incorporated in the ITER antenna electrical circuit (9).

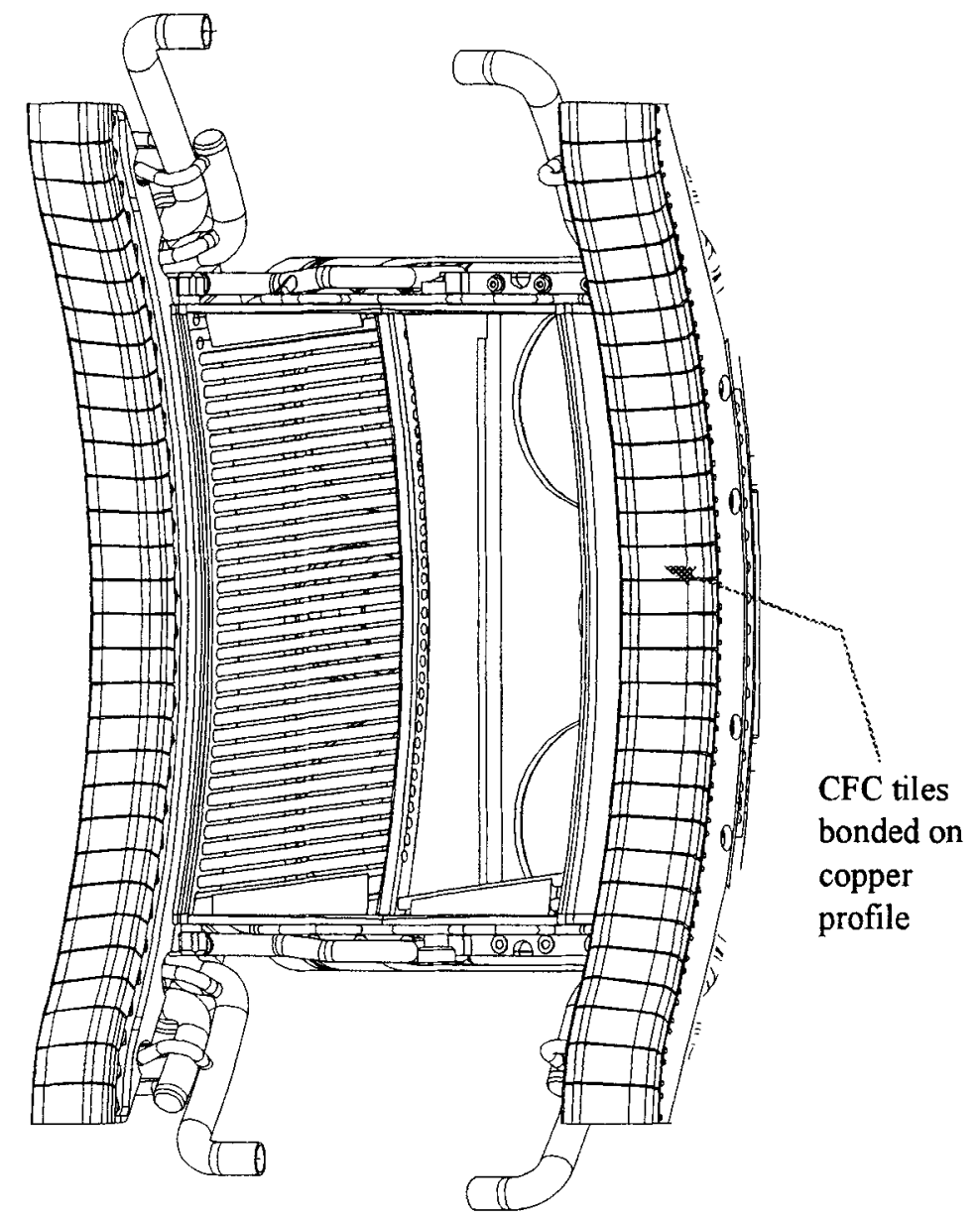

FIGURE 4. Artist view of the new lateral protection for ICRH and LHCD antennas, shown here surrounding an ICRH Antenna (Faraday shield partially omitted)

\section{LHCD System}

The TS LHCD system is using 2 multijunction launchers fed by 16 klystrons. Available source power amounts to a total of $8 \mathrm{MW}$. The present klystrons, designed for $500 \mathrm{~kW}$ and $210 \mathrm{~s}$ pulse length, have been tested up to $450 \mathrm{~kW}$ during $1000 \mathrm{~s}$. Developments at TTE are aiming at klystrons able to deliver 750 $\mathrm{kW}$ during $1000 \mathrm{~s}$ with VSWR $\leq 1.4$. any phase $(10)$. 
For reliable long pulse operation on TS, a new launcher is being constructed. It will use a larger frontal area in the port which will permit to launch $4 \mathrm{MW}$ through a single port at an average power density of $24 \mathrm{MW} / \mathrm{m}^{2}$. The fabrication of this new launcher is under way and it should be installed in 1999. This launcher will benefit of the developments for the ICRH lateral protections and will be equipped with the same elements. The multijunction array is fed through a mode converter from the rectangular waveguides. The design will allow to change the front part to an alternative configuration: the active passive waveguide array. This type of multijunction array features improved cooling capabilities at the expense of higher electrical fields for a comparable power level. This approach is a development for future long pulse operation (11).

\section{ECRH System}

The ECRH project for TS is aiming a power level of 3 MW delivered by 6 gyrotrons to the plasma through an antenna located in a horizontal port. The mirrors can be adjusted to aim at different poloidal and toroidal locations. Nominal pulse length is $210 \mathrm{~s}$ (12).

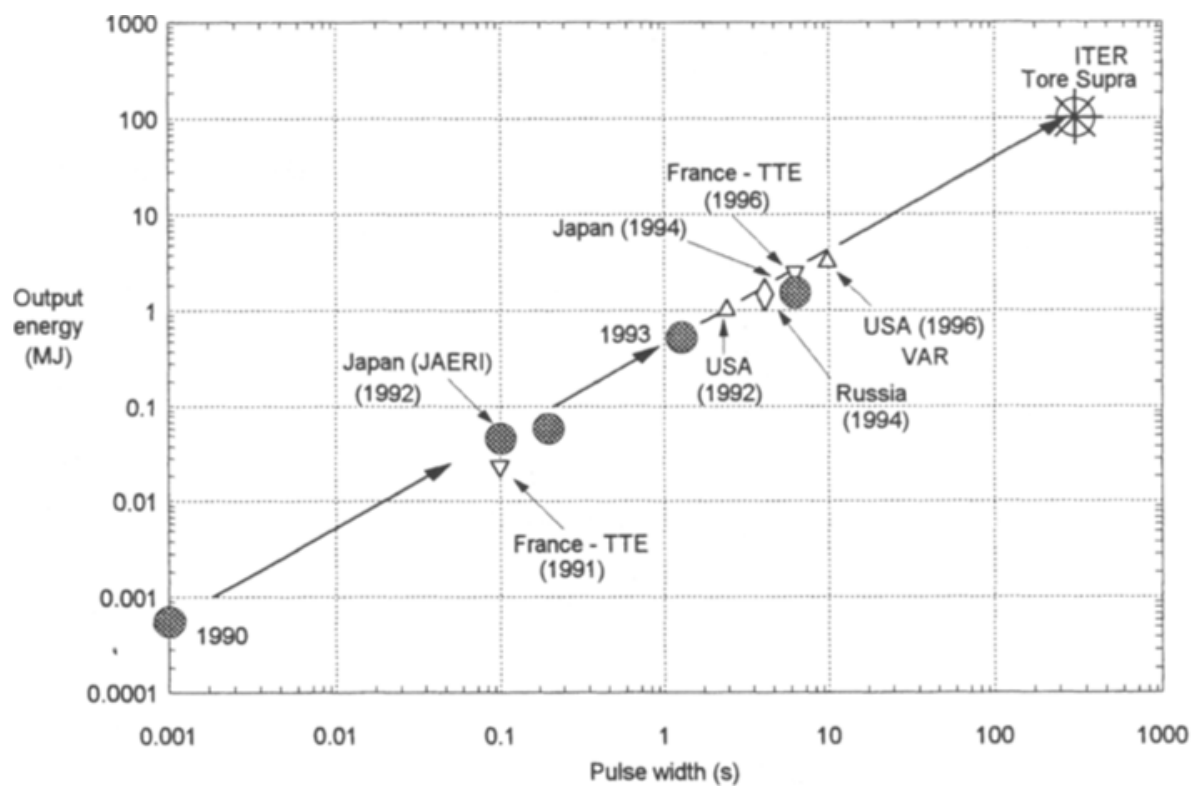

FIGURE 5. Gyrotron progress towards high energy pulses

The joint development undertaken by the CEA, the CRPP and TTE with technical support from FZK is now in its final phase, with the test of a full scale prototype. 
Latest results for this gyrotron at TTE have passed a $5 \mathrm{~s}$ test at $500 \mathrm{~kW}$ output power. Pulse length is limited at the factory by the test load capability. Longer tests will be performed when the first tube will be delivered and installed at Cadarache in the end of 1997 (13). Delivery of the series of tubes is expected during 1998. First partial power operation on the plasma is foreseen in mid 1998, and the full system should be operational after the end of 1998. In terms of energy delivered and pulse length, these sources are close to what is planned for ITER (Fig. 5).

\section{CONCLUSION}

Upgrades of ICRH systems are needed to meet the future long pulse operation requirements. These developments will tend to obtain reliable power injection from the various RF systems of Tore Supra, among which some have already proven to be very efficient tools for the control of plasma parameters.

The R\&D program on Tore Supra is aimed at developing a coherent solution for long pulse operation by mean of improvements of the power exhaust and particle control, as well as for power injection and plasma control systems. The technical solutions that will be tested on Tore Supra are of direct relevance for future machines.

\section{REFERENCES}

1. Peysson et al., "Long pulse RF experiments on Tore Supra : results and simulations", $6^{\text {th }}$ IAEA Fusion Energy Conference, Montréal, 1996.

2. T.Takizuka et al., "Threshold power and energy confinement for ITER", $6^{\text {th }}$ IAEA Fusion Energy Conference, Montréal, 1996.

3. G. Rey et al., "High power and long puise capability of the $3.7 \mathrm{GHz}$ LHCD system on ToreSupra", 17th SOFT, Rome, 1992.

4. T. Wijnands et al., "Feedback Control of the Current Profile on Tore Supra", 23th EPS, Kiev,1996.

5. V.Basiuk et al., "FWEH induced high bootstrap current on Tore Supra", this conference.

6. "Ciel Project", EUR FU(96) CCFP 69/8.3.

7. J.H.Harris et al., "Plasma-surface interactions with ICRF antennas and lower hybrid grills in Tore Supra", $12^{\text {th }}$ PSI Conference, St Raphael, 1996.

8. G.Agarici et al., "Sliding contact tests at high RF current under vacuum", 19th SOFT, Lisbon, 1996

9. ITER Detailed Design Document, section 5.1.

10.P. Froissard et al., "High performance results with the LHCD system on Tore Supra and new Launcher design for quasi continuous operation", 19th SOFT, Lisbon, 1996

11. P. Bibet et al., "New Launcher for Tore Supra LHCD", this conference

12. M.Pain et al., "Status of the ECRH System of Tore Supra", $18^{\text {th }}$ SOFT, Karlsruhe, 1994.

13. M.Pain et al., "Status of the $118 \mathrm{GHz}$ quasi-CW Gyrotron for the Tore Supra and TCV Tokamaks", 19th SOFT, Lisbon, 1996. 
G. Agarici, J. P. Allibert, J.M. Ané, R. Arslanbekov, J.F. Artaud, S. Balme, V. Basiuk, P. Bayetti, L. Baylor

1), B. Beaumont, A. Bécoulet, M. Benkadda 2), G. Berger-By, S. Bério, P. Bibet, J.P. Bizarro 3), S. Boeddeker, G. Bon-Mardion, J.M. Bottereau, F. Bottiglioni, S. Brémond, R. Brugnetti, R. V. Budny 4), Y. Buravand, H. Capes, J.J. Capitain, J.L. Carbonnier, J. Carrasco, P. Chappuis, E. Chatelier, M. Chatelier, J.H. Chatenet ${ }^{5)}$, F. Cherigier, D. Ciazynski, F. Clairet, L. Colas, J.J. Cordier, A. Côté ${ }^{6)}$, B. Couturier, J.P. Crenn, P. Cristofani, C. Deck, P. Decool, B. De Gentile, E De la Cal, H. Demarthe, C. De Michelis, P. Deschamps, C. Desgranges, P. Devynck, L. Doceul, C. Doloc, M. Dougnac, M. Druetta 7), M. Dubois, J.L. Duchâteau, L. Dupas, D. Edery, D. Elbèze, D. Escande, J.L. Farjon, J.R. Ferron 8), M. Fois, C. Forrest ${ }^{8}$ ), D. Fraboulet, V. Fuchs ${ }^{6}$, M. Fumelli, B. Gagey, L. Garampon, X. Garbet, E. Gauthier, A. Géraud, F. Gervais ${ }^{10)}$, P. Ghendrih, C. Gil, G. Giruzzi, M. Goniche, R. Gravier, B. Gravil, M. Grégoire, D. Grésillon ${ }^{10)}$, C. Grisolia, A. Grosman, D. Guilhem, B. Guillerminet, R. Guirlet, L. Guiziou, J. Harris 1), P. Hennequin 10), F. Hennion, P. Hertout, W.R. Hess, M. Hesse, G.T. Hoang, J. Hogan 1), W.A. Houlberg ${ }^{1)}$, T. Hutter, C. Jacquot, B. Jager, E. Joffrin, J. Johner, J.Y. Journeaux, P. Joyer, C. Klepper ${ }^{1)}$, F. Kazarian, H. Kuus, L. Ladurelle, D. Lafon, P. Laporte, J. Lasalle, L. Laurent, C. Laviron, G. Leclert 11), A. Ledyankine, P. Libeyre, M. Lipa, X. Litaudon, T. Loarer, P. Lotte, J.F. Luciani 5), T. Lutz 13), P. Magaud, W. Mandl, G. Martin, A. Martinez, E.K. Maschke, R. Masset, M. Mattioli, G. Mayaux, B. Meslin, Y. Michelot, P. Mioduszewski 1), J. Misguich, R. Mitteau, P. Mollard, P. Monier-Garbet, D. Moreau, F. Moreau, P. Moreau, J.P. Morera, B. Moulin, D. Moulin, M. Moustier, R. Nakach, F. Nguyen, R. Nygren 13), P. Ouvrier-Buffet, L. Owen 1), M. Pain, J. Pamela, F. Parlange, G. Pastor, R. Patris, M. Paume, A.L. Pecquet, B. Pégourie, Y. Peysson, D. Piat, P. Platz, C. Portafaix, M. Prou, A. Quéméneur ${ }^{10)}$, G. Rey, B. Rothan, R. Ruggieri, S.A. Sabbagh 16), R. Sabot, F. Samaille, B. Saoutic, Y. Sarazin, E. Sebelin, J. Schlosser, J.L. Segui, K. Soler, P.G. Senato 17), M. Spuig, Y. Stephan 18), J. M. Theis, M. Tokar ${ }^{19)}$, G. Tonon, A. Torossian, A. Truc ${ }^{10)}$, E. Tsitrone, B. Turck, S. Turlur, J.C. Vallet, D. VanHoutte, A. Verga ${ }^{2)}$,_H. Viallet, I. Voitsekovitch, J. Weisse, R. White ${ }^{4)}$, T. Wijnands, M. Zabiego, X.L. Zou

1) Oak Ridge National Laboratory, Oak Ridge, Tennessee, USA.

2) Equipe Turbulence Plasma, Institut Méditerranéen de Technologie, Marseille, France.

3) Instituto supérior tecnico, Association EUR-IST, Lisboa, Portugal.

4) Princeton Plasma Physics Laboratory, Princeton University, New Jersey, USA.

5) Centre de Physique Théorique, Ecole Polytechnique, France.

6) Centre Canadien de Fusion Magnétique, Varennes, Québec, Canada.

7) Laboratoire de Traitement du Signal et dInstrumentation, CNRS, St Etienne, France.

8) General Atomics, San Diego, Califomia, USA.

9) C.R.E. Association EUR-ENEA, Frascati, Italy.

10) Physique des Milieux Ionisés, Ecole Polytechnique, Palaiseau, France.

11) L.P.M.I., Université de Nancy I, Vandouvre les Nancy, France

12) Institute of Plasma Physics, Hefei, China.

13) Sandia National Laboratories, Albuquerque, New Mexico, USA.

14) Université Paris XI, Orsay, France.

15) Max Planck Institut fur plasmaphysick, Association EUR-IPP, Garching,

Deutschland.

16) Department of Applied Physics, Columbia University, New York, New York, USA.

17) C.S.Gas Ionizzati, Association EUR-ENE-CNR, Padova, Italy.

18) CISI Ingénierie, Centre d"Etudes de Cadarache, France

19) Association Euratom-KFA Jülich, Deutschland 